\title{
The Design of Oil Well Production Engineering Analysis System
}

\author{
Panpan Zhao, Xiufang Wang", Ying Liu, Mengmeng Wu and Wufeng Yue
}

School of Electrical \& Information Engineering, Northeast Petroleum University, Daqing, 163318, China

\begin{abstract}
With the rapid development of oilfield information construction, the requirements for the analysis of oil well production are also getting higher. The traditional method, which is by experience, cannot meet the demand of oilfield information construction for the analysis accuracy. Based on some common problems in the analysis of oil production, this paper designs and implements the oil well production engineering analysis system based on NET. The design of the system mainly includes two parts. One part is the calculation of temperature and pressure field of the wellbore and the other part is the drawing of system efficiency control chart. This system can provide the distribution results of temperature and pressure of the wellbore during the production process, and according to the system efficiency control chart, we can accurately determine the production situation of oil well. This system has the advantages of simple operation, accurate calculation, clear analytical results, and comprehensive analysis.
\end{abstract}

Keywords: System efficiency, wellbore pressure, wellbore temperature.

\section{INTRODUCTION}

With the rapid development of modern enterprise management, using computer analysis the state of an oil well during the production process is a part of the oilfield information construction, and is critical for the production safety of the oil well. In the process of exploitation of oil, the wellbore temperature and pressure distribution and system efficiency of oil well is an indispensable data.

There are many calculation methods of pressure distribution in wellbore, including Beggs-Brill method, MukherjeeBrill method, Orkiszewski method and Hagedorn-Brown method etc, but each method has its own scope of application. This system includes Beggs-Brill method, Orkiszewski method, and Hagedorn-Brown method; the user can choose suitable method according to different data, which can greatly improve the calculation accuracy. This system mainly researched the temperature field of the wellbore from two parts, one part is the temperature distribution in the wellbore of conventional pumping oil wells, and the other part is the temperature distribution in the wellbore of electrical heating wells. This system also can draw system efficiency control chart of pumping oil wells. According to the analysis results, we can take corresponding measures to improve the system efficiency.

\section{THE CALCULATION OF TEMPERATURE AND PRESSURE FIELD OF THE WELLBORE}

In the exploitation of oil, the temperature change and pressure change of the fluid in the wellbore directly affects the exploitation of crude oil. This part mainly forms the two parts to study, one part is the calculation of pressure field of the wellbore, and the other is the calculation of temperature field of the wellbore.

\subsection{The Calculation of Pressure Field of the Wellbore}

Crude oil and gas, produced from several thousand meters deep strata, most of the oil wells is not in the singlephase but gas and liquid(two-phase flow) or oil, gas, and water (three-phase flow). The research of multiphase pipe flow is important for the design of the oil production system and the gathering and transportation of the crude oil. Because of the complexity of multiphase flow, presently, for the calculation of the pressure drop, empirical formula or half experience formula based on the experiments are mostl used [1]. Such as, Duns-Ros method, Orkiszewski method, Hagedorn-Brown method and Beggs-Brill method etc have been widely used in the petroleum industry.

This system can calculate the wellbore pressure distribution in the Hagedorn-Brown method or Orkiszewski method or Beggs-Brill method, and draws the relation curve between pressure and well depth.

\subsubsection{Hagedorn-Brown Method}

The Hagedorn-Brown method is for the mixture of oil, gas, and water flows in a vertical tube. It calculates the pressure gradient according to the mechanical conservation law of single phase flow [2]. For the water content moderate wells, the method has good application in the calculation of pressure distribution of the wellbore.

The pressure drop equation of this method is as follows:

$$
\frac{d p}{d z}=\overline{\tilde{\mathrm{n}}} g+\ddot{\mathrm{e}} \frac{G^{2}}{2 D A^{2} \overline{\tilde{\mathrm{n}}}}
$$

In equation 1: $\quad \overline{\tilde{\mathrm{n}}}=\tilde{\mathrm{n}}_{L} H_{L}+\tilde{\mathrm{n}}_{g}\left(1-H_{L}\right) ; \quad G=G_{g}+G_{L}$ $=A\left(v_{s L} \tilde{\mathrm{n}}_{L}+v_{s g} \tilde{\mathrm{n}}_{g}\right) ; \tilde{\mathrm{n}}_{g}$ is the density of gas; $\tilde{\mathrm{n}}_{L}$ is the density 
of liquid; $\tilde{\mathrm{n}}$ is the density of mixture; $H_{L}$ is the liquid holdup; $g$ is the acceleration of gravity; $A$ is the cross-sectional area of the tube, $A=\partial D^{4} / 4 ; D$ is the diameter of the pipe column; $G$ is the mass flow of gas-liquid mixtures; $G_{g}$ is the mass flow of gas phase; $G_{L}$ is the mass flow of liquid phase; $v_{s g}$ is the gas phase apparent velocity, $v_{s g}=Q_{g} / A ; v_{s L}$ is the liquid phase apparent velocity of flow, $v_{s L}=Q_{L} / A ; Q_{g}$ is the volume flow rate of gas phase; $Q_{L}$ is the volume flow rate of liquid phase; $\ddot{e}$ is the two-phase frictional resistance coefficient.

\subsubsection{Beggs-Brill Method}

The Beggs-Brill method calculates the pressure gradient according to the energy conservation equation of homogeneous flow [3]. For the total water yield smaller oil wells, this method has a good application effect on the calculation of pressure continuity of wellbore. This method is suitable for various angles of pipeline, when the well deviates, this method is recommended for use.

In this method, in order to calculate the liquid holdup, first use the horizontal pipe to calculate, and then use the tilt correction coefficient calibration for the corresponding inclined pipe [4]. Different flow patterns have different tilt correction coefficients.

The pressure drop equation of this method is as follows:

$$
-\frac{d p}{d z}=\frac{\left[\tilde{\mathrm{n}}_{L} H_{L}+\tilde{\mathrm{n}}_{g}\left(1-H_{L}\right)\right] g \sin \mathrm{\textrm {e }}+\frac{\ddot{\mathrm{e}} G v}{2 D A}}{\left.1-\left\{\tilde{\mathrm{n}}_{L} H_{L}+\tilde{\mathrm{n}}_{g}\left(1-H_{L}\right)\right] v \cdot v_{s g}\right\} / P}
$$

In equation 2: $\tilde{\mathrm{n}}_{g}$ is the density of gas phase; $\tilde{\mathrm{n}}_{L}$ is the density of liquid phase; $H_{L}$ is the liquid holdup; è is the angle between the pipe and the horizontal plane; $G$ is the mass flow of gas-liquid mixtures; $\ddot{e}$ is the two-phase frictional resistance coefficient; $v$ is the average velocity of mixture; $v_{s g}$ is the gas phase apparent velocity; $A$ is the crosssectional area of the tube, $A=\partial D^{4} / 4 ; D$ is the diameter of the pipe column.

\subsubsection{Orkiszewski Method}

In the calculation of the pipe friction pressure gradient and density of gas-liquid mixture in the pipe, different methods are used according to different flow patterns [5]. The Griffith method is used in Bubbly flow. The Griffith-Wallis method is used in the density of the slug flow. The Orkiszewski method is used in the calculation of frictional pressure gradient. The Duns-Ros method is used in the transition zone of the slug flow and mist flow. Therefore, before calculating the total pressure gradient, we must first determine the flow patterns and then select the appropriate formula to calculate.

The pressure drop equation of this method is as follows:

$$
\frac{\ddot{\mathrm{A}} p}{\ddot{\mathrm{A}} z}=\left(\overline{\tilde{\mathrm{n}}} g+\hat{\mathrm{o}}_{f}\right) /\left(1+G Q_{g} / A^{2} \bar{P}\right)
$$

In equation $3: \tilde{\mathrm{n}}$ is the density of mixture; $g$ is the acceleration of gravity; $\mathrm{O}_{f}$ is the pipe friction pressure gradient; $G$ is the mass flow of gas-liquid mixtures; $Q_{g}$ is the volume flow rate of gas phase in the average pressure and average temperature; $A$ is the cross-sectional area of the tube; $\bar{P}$ is the average pressure.

Fig. (1) shows the interface design and experimental results.

\subsection{The Calculation of Temperature Field of the Well- bore}

In the exploitation process of oil, oil fluidity directly affects the production and the pump efficiency. The electric heating technology is often used to improve oil fluidity. The study of temperature distribution in wellbore is the basis of the analysis of crude oil fluidity, and also provides a method to determine the depth and the heating power. The system can calculate the temperature distribution in the wellbore of conventional pumping oil well and that of electrical heating well. The system can also provide the temperature distribution law from the comparison of the results [6].

\subsubsection{The Temperature Distribution in the Wellbore of Conventional Pumping Oil Wells}

When the stratigraphic fluid rises along the wellbore, due to the surrounding's stratigraphic heat dissipation, its temperature is gradually decreased. The bottom of the wells is taken as the origin of coordinates and the vertical upward is the positive. According to the energy balance equation:

$-W d t=K_{1}\left(t-t_{e}\right) d l$

In equation 4: $t_{e}=t_{r}-m l ; W=W_{o} C_{o}+W_{w} C_{w}+W_{g} C_{g}$

The general solution of formula 4 is as follows:

$t=C \exp \left(-\frac{K_{1} l}{W}\right)+\frac{m W}{K_{1}}+\left(t_{r}-m l\right)$

The integral constant $\mathrm{C}$ can be determined according to the boundary condition. When $l=0, t=t_{d}$ there is:

$t=\left[\left(t_{d}-t_{r}\right)-\frac{m W}{K_{1}}\right] \exp \left(-\frac{K_{1} l}{W}\right)+\left(t_{r}-m l\right)+\frac{m W}{K_{1}}$

Because the bottom temperature is equal to the formation temperature, namely $t_{r}=t_{d}$, therefore, there is:

$t=\frac{m W}{K_{1}}\left[1-\exp \left(-\frac{K_{1} l}{W}\right)\right]+\left(t_{r}-m l\right)$

\subsubsection{The Temperature Distribution in the Wellbore of Electrical Heating Wells}

In the establishment of temperature distribution model of electric heating wells, we need to consider two aspects. First, the temperature distribution from the bottom hole to the heating point; secondly, the temperature distribution from the heating point to the wellhead [7]. In the first aspect, the temperature distribution model is the same as conventional pumping oil well. When we establish the temperature distribution model from the heating point to the wellhead, we can intercept an infinitesimal element $d l$ along the well depth direction. The heat released by the heating device can be regarded as an internal heat source. The energy balance equation in the infinitesimal element is as follows: 


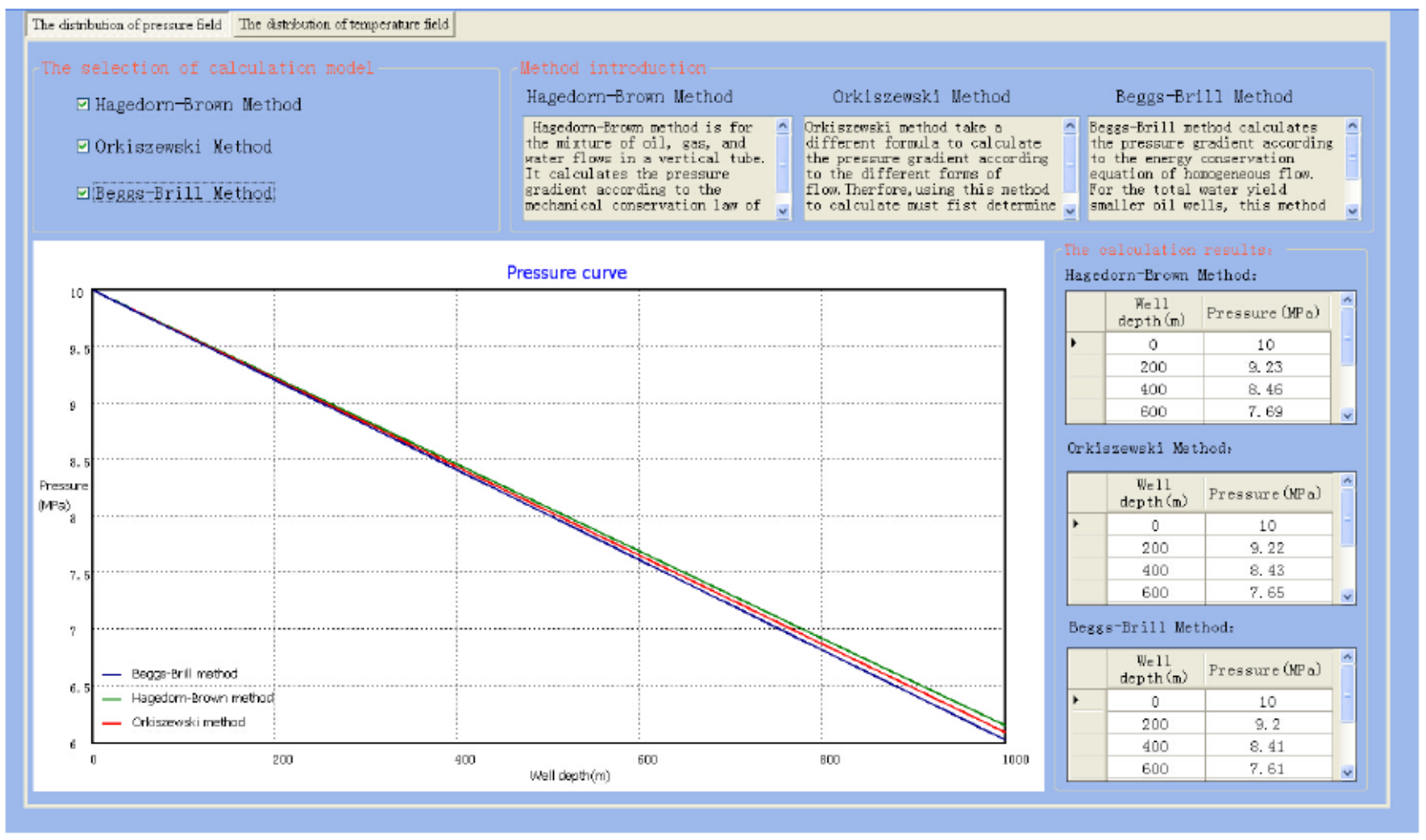

Fig. (1). The pressure field of the wellbore.

$$
\left\{K_{1}\left[t-\left(t_{r}-m l\right)\right]+\left(M_{f}+M_{g}\right) g-q_{i}\right\} d l=-W d l
$$

The general solution of formula 8 is as follows:

$$
t=C \exp \left(-\frac{K_{1} l}{W}\right)+\left(t_{r}-m l\right)+\left(W m+q_{i}\right) / K_{1}
$$

In the heating point, $l=0, t=t_{j}$. The temperature distribution from the heating point to the wellhead is as follows:

$$
t=\left(t_{j}-t_{r}\right) \exp \left(-\frac{K_{1} L}{W}\right)+\frac{\left(W m+q_{i}\right)}{K_{1}}\left[1-\exp \left(-\frac{K_{1} L}{W}\right)\right]+\left(t_{r}-m l\right)
$$

Therefore, the temperature distribution model of electric heating wells is as follows:

$$
\left\{\begin{aligned}
t= & \frac{m W}{K_{1}}\left[1-\exp \left(-\frac{K_{1} l}{W}\right)\right]+\left(t_{r}-m l\right) \\
& (\text { From the bottom hole to the heating point) } \\
t= & \left(t_{j}-t_{r}\right) \exp \left(-\frac{K_{1} L}{W}\right)+\frac{\left(W m+q_{i}\right)}{K_{1}}\left[1-\exp \left(-\frac{K_{1} L}{W}\right)\right]+\left(t_{r}-m l\right)
\end{aligned}\right.
$$

(From the heating point to the wellhead)

In equation 4 to equation 10: $W$ is the output of the equivalent; $W_{o}$ is the mass flow of oil; $W_{w}$ is the mass flow of water; $W_{g}$ is the mass flow of gas; $C_{o}$ is the specific heat of oil; $C_{w}$ is the specific heat of water; $C_{g}$ is the specific heat of gas; $K_{1}$ is the heating transfer coefficient per unit length; $t_{e}$ is the stratigraphic temperature along the wellbore; $t$ is the temperature of liquid; $t_{d}$ is the temperature of the liquid produced in the bottom hole; $q_{i}$ is the internal heat source; $t_{r}$ is the stratigraphic temperature in the bottom hole; $m$ is the stratigraphic temperature gradient. sults.

Fig. (2) shows the interface design and experimental re-

\section{THE SYSTEM EFFICIENCY CONTROL CHART}

During the oil production process, along with the prolonged working life of oil wells, as well as the aging and wearing of some mechanical parts, system efficiency is generally reduced. System efficiency is an important indicator for evaluating the energy consumption of pumping wells [8]. Currently in the calculation and management of the system efficiency of pumping wells still uses the results of a single well to analyze and judge, whose work efficiency is not high [9]. In order to better grasp the overall situation of pumping well system efficiency, we should establish macro control charts for the well system efficiency. Making timely analysis of the problematic well and takin appropriate measures to improve the system efficiency which provides an important basis for production management and decision-making [10]. This module mainly studies the above aspects, design a set of suitable macroeconomic management method of pumping wells system efficiency, which is more intuitive.

By combining the actual situation of oil production and establishing the system efficiency mathematical model and boundary condition of pumping wells this module achieves the block management of pumping wells system efficiency, 


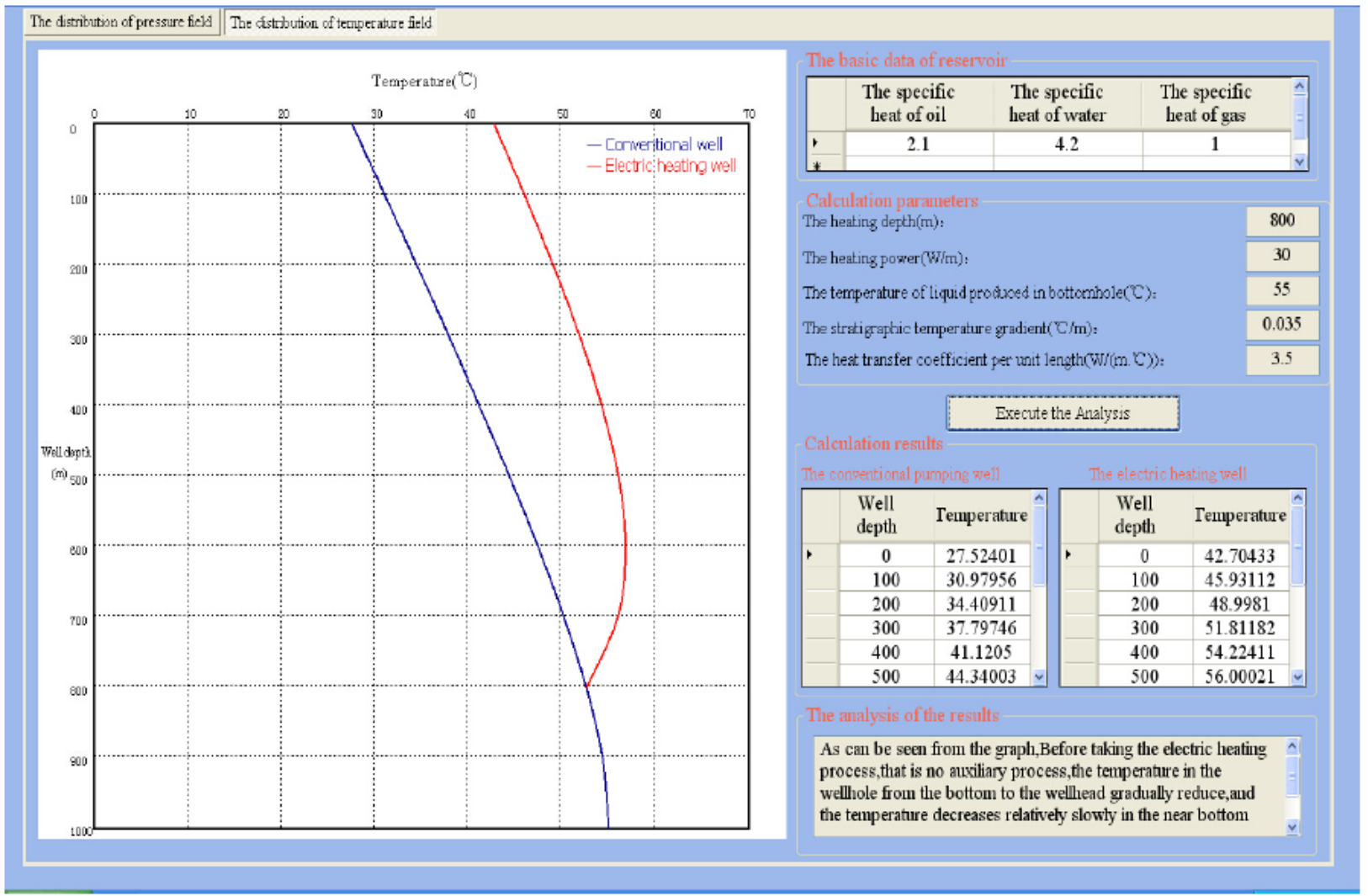

Fig. (2). The temperature field of the wellbore.

mainly based on the basic formula for calculating the system efficiency of pumping wells [11]. Finally, we take system efficiency on the vertical axis, pressure on horizontal axis. Draw a control chart rendering the system efficiency. According to the explanation of each module in control charts, we can take appropriate measures to take the system efficiency into the reasonable area.

\subsection{The Establishment of Mathematical Model}

$\zeta=\frac{M\left(l-103.4 P_{1}+103.4 P_{2}\right) P_{1}}{0.585 P_{1}+0.086 k\left(1-f_{w}\right)}$

$$
\text { In equation 11: } M=\frac{B f_{r}}{1.39 l\left(f_{r}-f_{t}\right)} \text {; }
$$

$B=\left[1-\frac{f_{r} v l^{2}}{S E}\left(\frac{1}{f_{r}}+\frac{1}{f_{t}}\right) \times 10^{-1}\right] \times 0.9897(1-0.191 / S) \sqrt{b^{2}-4 a c} ;$

Ç is the system efficiency ; $P_{1}$ is sank pressure ; $l$ is pump setting depth; $k$ is oil and gas volume ratio; $f_{w}$ is the mass fraction of water; $f_{t}$ is the diameter of the sucker rod; $f_{r}$ is tubing diameter; $S$ is the length of stroke; $v$ is mixed liquid density; $P_{2}$ is oil pressure; $E$ is elasticity coefficient, and its value is $2.0 \times 10^{11} \mathrm{~Pa}$.

\subsection{The Determination of the Boundary Conditions}

Boundaries are determined based on the above mathematical model, combining with the specific circumstances of the oilfield reservoir.
Fig. (3) shows the boundary line of system efficiency control chart of pumping wells.

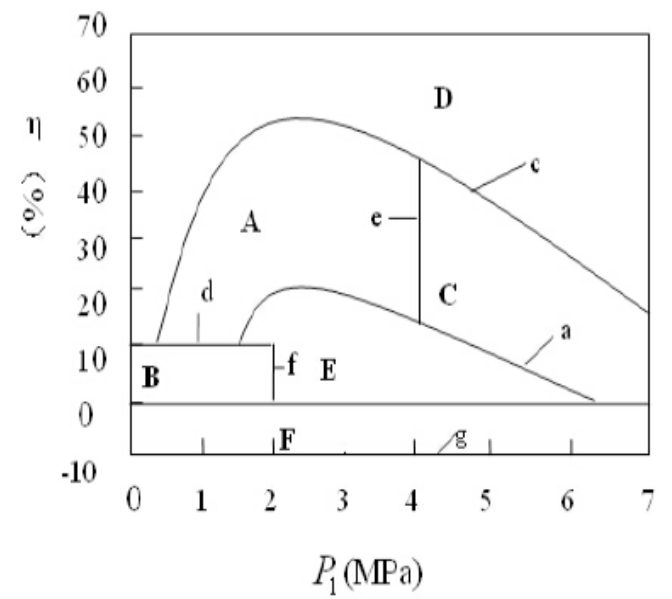

Fig (3). The boundary line of system efficiency control chart of pumping wells.

The meaning of each region in Fig. (3) are as follows:
A: Reasonable area
B: The area that has large parameters
$\mathrm{C}$ : The area that has small parameters
D: The area that data need to be inspected
E: Maintain and extract area
F: Flowing area 
The meaning of each line in Fig. (3) are as follows:

$a$ Line: The theoretical lower limit of system efficiency.

Choose the smallest block pump depth, minimum water content and the lowest ratio of oil and gas to calculate system efficiency. That is $c=f\left(L, f_{w}, k, P_{1}\right)$, where $L=600 m$; $f_{w}=60 \% ; k=300$.

$c$ Line: The theoretical upper limit of system efficiency.

Choose the biggest block pump depth, maximum water content and the highest ratio of oil and gas to calculate system.

That is $c ̧=f\left(L, f_{w}, k, P_{1}\right)$, where $L=800 m ; f_{w}=95 \%$; $k=600$.

$d$ Line: The reasonable bound line of system efficiency. $\zeta=10 \%$

$e$ Line: the allowed upper limit of sinking pressure.

$P_{1}=4.0 \mathrm{MPa}$

$f$ Line: the allowed lower limit of sinking pressure.

$P_{2}=2.0 \mathrm{MPa}$

$g$ Line: the negative lower limit of system efficiency.

$c=-10 \%$

The reference data of calculating system efficiency are shown in Table 1.

Fig. (4) shows the interface design and experimental results.

Table 1. The reference data of calculating system efficiency.

\begin{tabular}{|c|c|c|c|c|c|c|c|c|}
\hline $\begin{array}{c}\text { Pump } \\
\text { Depth(m) }\end{array}$ & $\begin{array}{c}\text { Ratio of Oil } \\
\text { and Gas }\end{array}$ & $\begin{array}{c}\text { Mass Fraction } \\
\text { of Water }\end{array}$ & $\begin{array}{c}\text { Diameter of the } \\
\text { Sucker Rod } \\
(\mathbf{m m})\end{array}$ & $\begin{array}{c}\text { Tubing Diame- } \\
\text { ter (mm) }\end{array}$ & $\begin{array}{c}\text { Length of } \\
\text { Stroke (m) }\end{array}$ & $\begin{array}{c}\text { Mixed Liquid } \\
\text { Density } \\
\left(\mathrm{kg} / \mathrm{m}^{3}\right)\end{array}$ & Oil Pressure & Sank Pressure \\
\hline \hline 760 & 350 & 0.8 & 19 & 62 & 4.17 & 0.89 & 0.45 \\
\hline 800 & 400 & 0.87 & 16 & 65 & 4.35 & 0.85 & 0.35 \\
\hline 800 & 360 & 0.9 & 19 & 63 & 4.2 & 0.87 & 0.42 & 3.47 \\
\hline 800 & 550 & 0.86 & 16 & 64 & 4.32 & 0.85 & 0.32 & 4.2 \\
\hline 800 & 400 & 0.84 & 13 & 64 & 5.5 & 0.84 & 0.45 & 5.5 \\
\hline 800 & 600 & 0.82 & 13 & 72 & 5.34 & 0.85 & 0.45 & 6 \\
\hline 700 & 340 & 0.82 & 19 & 60 & 5.45 & 0.89 & 0.21 & 0.5 \\
\hline 750 & 320 & 0.89 & 13 & 68 & 5.34 & 0.84 & 0.5 \\
\hline
\end{tabular}
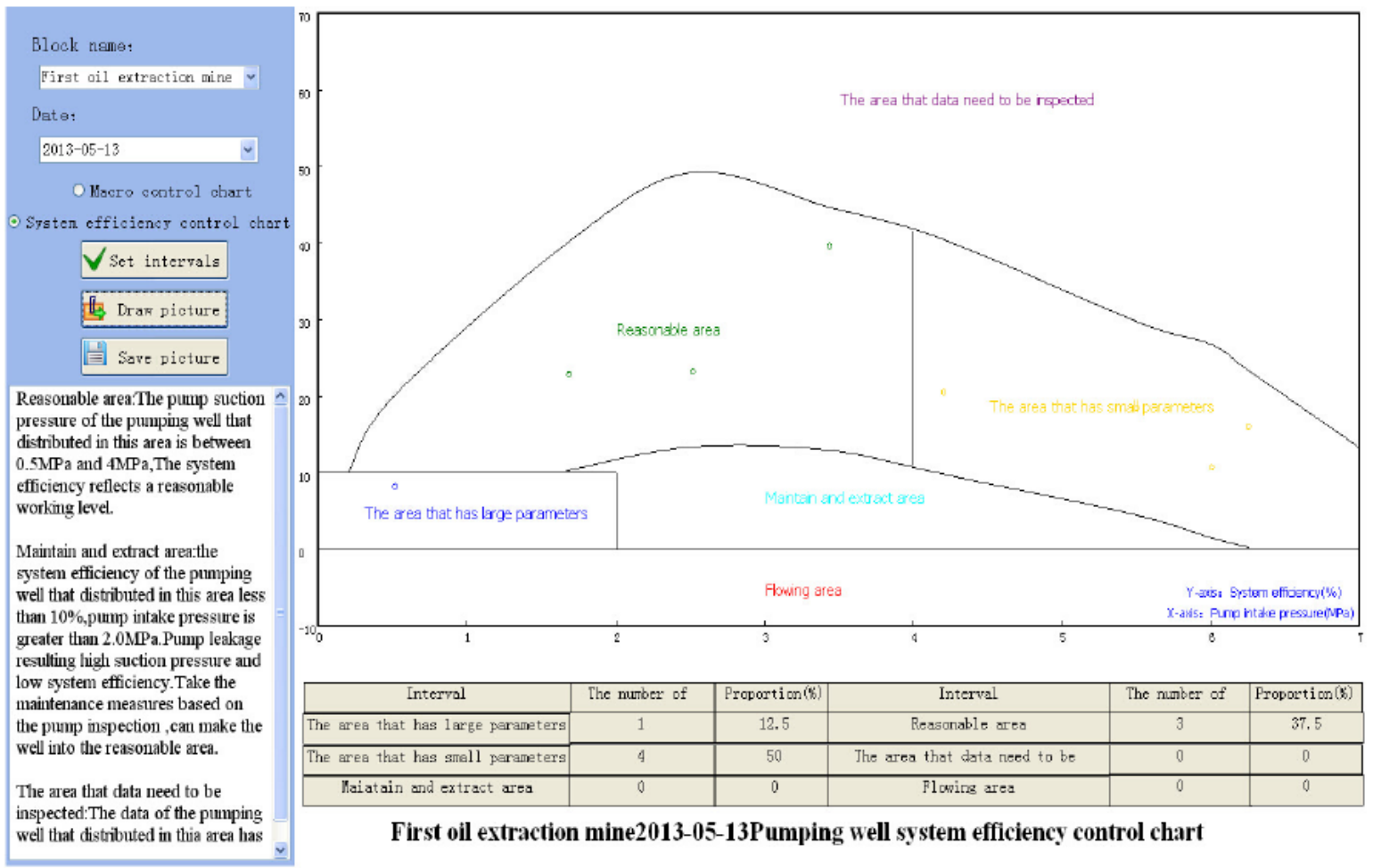

First oil extraction mine2013-05-13Pumping well system efficiency control chart

Fig. (4). System efficiency control chart. 


\section{CONCLUSION}

In terms of production wells, this system analyzes two aspects such as the temperature calculation within the wellbore pressure field and system efficiency, combined with some common problems in the oil production processes. The results of this system not only can be used to guide the design of system construction process, but also can be used to improve the system efficiency of the pumping wells.

Fast and accurate calculation, simple operation, and friendly interface, the system has good practicality, provides a reliable base for the analysis of oil production. Utilizing the system can improve efficiency and quality significantly.

\section{CONFLICT OF INTEREST}

The authors confirm that this article content has no conflicts of interest.

\section{ACKNOWLEDGEMENTS}

This work is supported by the National Science \& Technology Support Plan Major Project under Grant No. 2012BAH12B03.

\section{REFERENCES}

[1] Y. Xichong, Z. Jinzhou, and W. Yaling, "Studying status and development direction for multiple pipe flow", China Offshore Oil and Gas (Engineering), vol. 14, no. 5, pp. 31-33, 2002.
[2] O. Flanigan, "Effect of uphill flow on pressure drop in design of two-phase gathering systems", Oil \& Gas Journal, vol. 61, no. 37, pp. 110-113, 1963.

[3] H.D. Beggs, and J.P. Brill, “ A study of two phase flow in inclined pipe”, Journal of Petroleum Technology, vol. 25, no. 5, 1973.

[4] K. Aziz, G.W. Govier, and M. Fogarasi, "Pressure drop in wells producing oil and gas", Journal of Canadian Petroleum Technology, vol. 17, no. 9, pp. 38-48, 1972.

[5] A.R. Hagedorn, and K.E. Brown, "Experimental study of pressure gradients occurring during continuous two-phase flow in smalldiameter vertical conduits", Journal of Petroleum Technology, vol. 13, no. 4, pp. 475-483, 1965.

[6] D. Wen, "The application of wellbore temperature distribution in the electric heating well", Science Technology and Engineering, vol. 12, no. 26, pp. 6782-6783, 2012.

[7] S. Shiquan, Z. Gongshe and L. Jingjing, "Calculation of temperature distribution of electrical heating rod in pumping well", FaultBlock Oil Gas Field, vol. 15, no. 3, pp. 121-123, 2008.

[8] D. Shimin and F. Nana, "Computer simulation model of the system efficiency of rod pumping wells", Journal of System Simulation, vol. 19, no. 8, pp. 1853-1856, 2007.

[9] Y. Liang, W. Zhongxing and Z Yan, "Study on system efficiency control chart of pumping wells", Petroleum Geology \& Oilfield Development in Daqing, vol. 18, no. 4, pp. 38-40, 1999.

[10] H. Jianmin, Y. Liang and T. Yanyan, "Drawing of system efficiency control graphics of pumping unit well", Journal of Daqing Petroleum Institute, vol. 24, no. 2, pp. 47-48, 2000.

[11] The Oil and Gas Industry Standard of the People's Republic of China SY/T5793-93. Test and Calculation of the Efficiency of Artificial Lift System. Petroleum Industrial Publishing House, Beijing, pp.1-10, 1994.

Received: April 21, 2015
(C) Zhao et al.; Licensee Bentham Open.

Revised: May 17, 2015

Accepted: June 01, 2015

This is an open access article licensed under the terms of the Creative Commons Attribution Non-Commercial License (http://creativecommons.org/licenses/by-nc/3.0/) which permits unrestricted, non-commercial use, distribution and reproduction in any medium, provided the work is properly cited. 